NBER WORKING PAPER SERIES

\title{
OPTIMIZING THE RETIREMENT PORTFOLIO: ASSET ALLOCATION, ANNUITIZATION, AND RISK AVERSION
}

\author{
Wolfram J. Horneff \\ Raimond Maurer \\ Olivia S. Mitchell \\ Ivica Dus \\ Working Paper 12392 \\ http://www.nber.org/papers/w12392
NATIONAL BUREAU OF ECONOMIC RESEARCH
1050 Massachusetts Avenue
Cambridge, MA 02138
July 2006

This research was conducted with support from the Social Security Administration via the Michigan Retirement Research Center at the University of Michigan under subcontract to the Johann Wolfgang Goethe-University of Frankfurt and a TIAA-CREF Institute grant to the National Bureau of Economic Research. Additional support was provided by the Pension Research Council at The Wharton School of the University of Pennsylvania and the Fritz-Thyssen Foundation. Opinions and errors are solely those of the authors and not of the institutions with whom the authors are affiliated. This is part of the NBER Program on the Economics of Aging. The views expressed herein are those of the author(s) and do not necessarily reflect the views of the National Bureau of Economic Research.

(O2006 by Wolfram J. Horneff, Raimond Maurer, Olivia S. Mitchell and Ivica Dus. All rights reserved. Short sections of text, not to exceed two paragraphs, may be quoted without explicit permission provided that full credit, including $\odot$ notice, is given to the source. 
Optimizing the Retirement Portfolio: Asset Allocation, Annuitization, and Risk Aversion Wolfram J. Horneff, Raimond Maurer, Olivia S. Mitchell and Ivica Dus

NBER Working Paper No. 12392

July 2006

JEL No. G22, G23, J26, J32, H55

\begin{abstract}
$\underline{\text { ABSTRACT }}$
Retirees must draw down their accumulated assets in an orderly fashion so as not to exhaust their funds too soon. We derive the optimal retirement portfolio from a menu that includes payout annuities as well as an investment allocation and a withdrawal strategy, assuming risk aversion, stochastic capital markets, and uncertain lifetimes. The resulting portfolio allocation, when fixed as of retirement, is then compared to phased withdrawal strategies such a "self-annuitization" plan or the 401(k) "default" pattern encouraged under US tax law. Surprisingly, the fixed percentage approach proves appealing for retirees across a wide range of risk preferences, supporting financial planning advisors who often recommend this rule. We then permit the retiree to switch to an annuity later, which gives her the chance to invest in the capital market and "bet on death." As risk aversion rises, annuities first crowd out bonds in retiree portfolios; at higher risk aversion still, annuities replace equities in the portfolio. Making annuitization compulsory can also lead to substantial utility losses for less risk-averse investors.
\end{abstract}

Wolfram J. Horneff

Johann Wolfgang Goethe-University of

Frankfurt

Department of Finance

Kettenhofweg 139 (Uni-PF 58), 60054 Frankfurt

GERMANY

horneff@finance.uni-frankfurt.de

Raimond Maurer

Johann Wolfgang Goethe-University of

Frankfurt

Department of Finance

Kettenhofweg 139 (Uni-PF 58), 60054 Frankfurt

GERMANY

rmaurer@wiwi.uni-frankfurt.de
Olivia S. Mitchell

The Wharton School

University of Pennsylvania

3620 Locust Walk, St 3000 SHDH

Philadelphia, PA 19104

and NBER

mitchelo@wharton.upenn.edu

Ivica Dus

Johann Wolfgang Goethe-University of

Frankfurt

Department of Finance

Kettenhofweg 139 (Uni-PF 58),

60054 Frankfurt

GERMANY

dus@finance.frankfurt-uni.de 


\title{
Optimizing the Retirement Portfolio: Asset Allocation, Annuitization, and Risk Aversion
}

\author{
WOlFRAM J. HORNEFF, RAIMOND MAURER, OLIVIA S. MitCHELl, AND IVICA DUS
}

Baby Boomers nearing retirement are now targeted by competing financial service providers seeking to help them manage their money in their golden years. Employer-based pensions are also switching from defined benefit to defined contribution plans, further underscoring retirees' need for insights regarding how they might convert their accumulated assets into a stream of retirement income without exhausting their funds too soon. On the one hand, insurers offer life annuities as the preferred distribution mechanism. On the other, mutual fund providers propose phased withdrawal plans as the better alternative. This paper compares different retirement payout approaches to show how people can optimize their retirement portfolios by simultaneously using investment-linked retirement rules along with life annuities.

To explore this issue, we first evaluate payout products using the "default" pattern adopted under US tax law for defined contribution or 401(k)-type pension portfolios. This permits us to determine whether these withdrawal rules suit a broad range of investors, and we illustrate the drawback of standardizing withdrawal rules. Next, we show that retirement planning would not involve a simple choice between annuitizing all one's money versus selecting a phased withdrawal plan, but rather it requires a combined portfolio consisting of both annuities and mutual fund investments. Using a lifetime utility framework, we compare the value of purchasing a stand-alone life annuity versus a phased withdrawal strategy backed by a properly diversified investment portfolio, as well as combinations of these two products. This framework also enables us to demonstrate the welfare implications of making annuitization compulsory at a specific age, as is currently the case in Germany and the UK.

\section{Prior Studies}

The simplest form of life annuity is a bond-like investment with longevity insurance protecting the retiree from outliving her resources, guaranteeing lifetime level payments to the annuitant. ${ }^{1}$ Insurers hedge these contracts by pooling the longevity risks across a group of annuity purchasers. Standard economic theory teaches us that life annuities will be valued by

\footnotetext{
${ }^{1}$ Accordingly, life annuities are similar to public defined benefit pensions with respect to their payout structure.
} 
risk-averse retirees, inasmuch as these contracts provide a steady income for life and hence they protect the retiree against the risk of exhausting her assets. ${ }^{2}$ Thus Yaari (1965) showed that the retiree maximizing a time separable utility function without a bequest motive would buy annuities with all her wealth, given a single risk-free asset and facing actuarially fair annuities; the approach has been extended by Davidoff et al. (2005) who again predicts full annuitization. Yet available evidence from most countries indicates that very few retirees actually purchase annuities with their disposable wealth.

Efforts to explain this so-called "annuity puzzle" have noted some disadvantages of annuitization; for example, buyers lose liquidity because the assets usually cannot be recovered even to meet special needs (e.g. in the case of poor health; c.f. Brugiavini 1993). The presence of a bequest motive also reduces retiree desires to annuitize wealth, and in the US, more than half of the elderly anticipate leaving a bequest worth more than $\$ 10,000$ (Bernheim, 2001; Hurd and Smith, 1999). Other explanations for why people may be reluctant to buy annuities include high insurance company loadings; the ability to pool longevity risk within families; asymmetric mortality expectations between annuity buyers and sellers; and the existence of other annuitized resources (e.g. Social Security or employer-sponsored pensions; c.f. Brown and Poterba, 2000; Mitchell et al., 1999). In addition, annuities appear relatively expensive in a low interest rate environment, as compared to equity-based mutual fund investments. And it also must be noted that, in the US at least, many payout annuities sold by commercial insurers are fixed in nominal terms, so the annuity purchaser does not participate in stock market performance (c.f. Davidoff et al., 2005).

Another reason people may not annuitize is that they believe they will do better by continuing to invest their retirement assets, making withdrawals periodically over their remaining lifetimes. Doing this is not so simple, however, as the retiree must select both an investment strategy - how much to invest in stocks and bonds - and a withdrawal rate, spelling out how much of her balance to spend per year. Financial advisors often recommend "rules of thumb," for instance dividing the portfolio roughly $60 \%$ stocks $/ 40 \%$ bonds and a spending rule of $4-5 \%$ of the balance per year (Polyak, 2005; Whitaker, 2005). Compared to buying a fixed life annuity, such an investment-linked phased withdrawal strategy has several advantages: it provides greater liquidity, participation in capital market returns, possibly higher consumption

\footnotetext{
${ }^{2}$ See the studies reviewed in Mitchell et al. (1999).
} 
while alive, and the chance of bequeathing assets in the event of early death. Yet a phased withdrawal tactic also exposes the retiree to investment risk and it offers no longevity pooling, so the retiree could possibly outlive her assets before her uncertain date of death. Thus any withdrawal plan which includes some risky investments and also requires the retiree to draw a fixed amount from her account each period involves a strictly positive probability of hitting zero before the retiree dies. The risk of running out of money can be partially mitigated by linking the drawdown to the fund balance each period, though of course this will produce benefit fluctuations which might fall substantially below what the life annuity payment would have been.

Prior studies have compared the pros and cons of specific phased withdrawal plans with life annuities that pay fixed benefits (see Table 1). For instance, some authors calculate the probability of running out of money before the retiree's uncertain date of death, using assumptions about age, sex, capital market performance, and initial consumption-to-wealth ratios. $^{3}$ These analyses also show how an optimal asset mix can be set to minimize the probability of zero income. Follow-on work by Dus et al. (2005) extended this research by quantifying risk and return profiles of fixed versus variable withdrawal strategies using a shortfall framework. On the return side, that study quantified the expected present value of the bequest potential and the expected present value of benefit payments; conversely, it measured the risk as the timing, probability, and magnitude of a loss when it occurs, compared to a fixed annuity benchmark.

\section{Table 1 here}

A natural next question to address is whether retirees might benefit from following a mixed strategy, where the portfolio might involve both a life annuity and a withdrawal plan. A mixed strategy seems intuitively appealing as it reduces the risk of payments falling below an annuity benchmark and it also enhances payouts early on. ${ }^{4}$ It is also interesting that some governments have mandated that tax-qualified retirement saving plans include a mandatory annuity that starts after an initial phased withdrawal phase. For example, in the UK, accumulated

\footnotetext{
${ }^{3}$ See for instance Albrecht and Maurer (2002); Ameriks et al. (2001); Bengen (1994, 1997); Chen and Milevsky (2003); Ho et al. (1994); Hughen et al. (2002); Milevsky (1998, 2001); Milevsky and Robinson (2000); Milevsky et al. (1997); and Pye (2000, 2001).

${ }^{4}$ See Blake et al. (2003); Milevsky and Young (2002); Kingston and Thorp (2005); Milevsky et al. (2006); and Dus et al. (2005). An alternative tactic would be to annuitize gradually (c.f. Kapur and Orszag, 1999); Milevsky and Young (2003) show that purchasing constant life annuities is a barrier control problem.
} 
pension assets had to be mandatorily annuitized by age 75 (this rule expired in 2006).

Germany's "Riester" plans provide a tax inducement if life annuity payments begin to pay out at age 85 (withdrawn amounts must either be constant or rising, prior to annuitization.) In the US, of course, annuitization is not compulsory for 401(k) plans; as a result, most retirees roll them over to an Individual Retirement Account and manage the funds themselves, subject to the tax laws requiring minimum distributions to begin at age $701 / 2$.

Despite the growing interest in the retirement payout problem, prior studies have not yet fully evaluated the pros and cons of purchasing a stand-alone life annuity versus a phased withdrawal strategy backed by a properly diversified investment portfolio, as well as combinations of these two products. In what follows, we show that the appropriate mix depends on the retiree's attitude toward risk as well as key assumptions regarding the capital market and actuarial tables.

\section{Comparing Alternative Payout Rules}

Our model assumes that the retiree is endowed with an initial level wealth $V_{0}$. This can be either used to purchase at cost $P R_{0}$ a single-premium life annuity-due paying a constant nominal annual benefit, or to finance a phased-withdrawal schedule of payments until the funds are exhausted (Dus et al., 2005). In what follows, we focus on the case of the female retiree, inasmuch as longevity risk is more important for women than for men.

The Constant Life Annuity. When the consumer purchases a life annuity, it pays her a constant amount $A_{t}$ conditional on her survival: $A=A_{t}=P R_{t} \cdot \ddot{a}_{x}^{-1}$. Using the actuarial principle of equivalence, we can determine the gross single premium of the annuity by calculating the present value of expected benefits paid to the annuitant (including expense loadings). The annuity factor $\ddot{a}_{x}$ for the retiree of age $\mathrm{x}$ is given by: ${ }^{5}$

$$
\ddot{a}_{x}=\sum_{t=0}^{w-x-1}(1+\delta)_{t} p_{x} \cdot\left(1+r_{t}\right)^{-t}
$$

where $w$ is the assumed last age (radix) of the mortality table; ${ }_{t} p_{x=} p_{x} \ldots . p_{x+t-1}$ is the probability that a retiree of age $x$ will survive to age $x+t$, where $p_{x}$ are the year-to-year survival probabilities for an individual aged $\mathrm{x} ; \delta$ is the expense factor; and $r_{t}$ is the yield on a zero

\footnotetext{
${ }^{5}$ Here we restrict our analysis to constant nominal annuities during the payout phase; further research will consider variable annuities.
} 
coupon bond maturing at time $t$ taken from the current interest rate term structure. ${ }^{6}$ Survival probabilities used to price the annuity are taken the female US Annuitant 2000 mortality table provided by the Society of Actuaries. Given these assumptions, and an expense factor of 7.3 percent (Mitchell et al., 1999), we compute the yearly fixed nominal payout at the beginning of each year for life as $\$ 7.2$ per $\$ 100$ premium. $^{7}$

This constant payout life annuity constitutes an asset class with a unique return profile, as payments are conditional on the annuitant's survival. The capital of those who die is allocated across surviving members of the cohort. Accordingly, a survivor's one-period total return from an annuity is a function of her capital return on the assets plus a mortality credit. Other things equal, the older the individual, the higher is the mortality credit.

Alternative Phased Withdrawal Plans. If the retiree instead pursued a phased withdrawal plan, she can select either a fixed or a variable withdrawal pattern. If she elects the fixed benefit $\underline{\text { approach}}$, she will pay herself a constant benefit $B_{t}=\min \left(B, V_{t}\right)$ until she dies or exhausts her retirement assets (here $V_{t}$ is the value of the retirement wealth at the beginning of year $t=0,1, \ldots$ just before that year's payment). In what follows, $B_{t}$ is set to equal the initial payout of a life annuity available for the same initial value $V_{t}$. The idea of the fixed benefit rule is to replicate the payout from a life annuity as long as the funds permit (sometimes termed a "self-annuitization" strategy), while at the same time retaining liquidity and some bequest potential in the event of an early death. Of course the risk of such a self-annuitization strategy is that poor investment returns could drive $V_{t}$ to zero while the retiree is still alive.

If she elects a variable phased withdrawal plan, several options are available. The three we explore in detail here are the fixed percentage rule, the $\underline{1 / T \text { rule, }}$, and the $\underline{1 / \mathrm{E}(T) \text { rule. Under }}$ the first, a constant fraction is withdrawn each period from the remaining fund wealth; that is, the benefit-wealth ratio is fixed over time so that:

$$
\frac{B_{t}}{V_{t}}=\omega_{t}=\omega .
$$

This withdrawal rule has the advantage of simplicity, requiring no information regarding the maximum possible duration of the payout phase or the retiree's personal characteristics. For example, $\omega$ can be set at the fraction which equals the life annuity payout divided by initial

\footnotetext{
${ }^{6}$ To model the term structure of risk free interest rates we assume a Vasicek model and use the corresponding spot rates to specify the discount factors. Details on parameterization are given in Appendix A.

${ }^{7}$ This is consistent with current quotes; see http://www.immediateannuities.com/
} 
wealth. ${ }^{8}$ Alternatively, the $1 / T$ rule determines the withdrawal fraction according to the maximum possible duration of the plan, or for example, to the oldest age in a mortality table. Therefore the withdrawal fraction under the $1 / T$ framework is not constant but rather rises with age. Formally, the benefit-wealth ratio at the beginning of year $t(t=0,1, \ldots T-1)$ of this retirement plan is given according to:

$$
\frac{B_{t}}{V_{t}}=\omega_{t}=\frac{1}{T-t} .
$$

Finally, the $1 / \mathrm{E}(T)$ withdrawal rule takes into account the retiree's remaining life expectancy in a dynamic way. Then, for a retiree of age $\mathrm{x}$, her benefit-to-wealth ratio in period $t$ conditional on survival is given as: ${ }^{9}$

$$
\frac{B_{t}}{V_{t}}=\omega_{t}=\frac{1}{\mathrm{E}[T(x+t)]}
$$

The shorter is her expected remaining lifetime $\mathrm{E}[T(x+t)]$, the higher the fraction that she will withdraw from her account. The $1 / \mathrm{E}(T)$ withdrawal rule is akin to the $401(\mathrm{k})$ rule, requiring retirees to begin consuming assets from age $701 / 2$ to ensure that they will consume their taxqualified pension accounts instead of leaving them as bequests for their heirs. The female US 2000 Annuitant Table is used for expected remaining lifetimes.

Figure 1 displays the retiree's withdrawal rate for the three variable withdrawal rules. The flat line for the fixed percentage rule contrasts with the rising fraction with age for both the $1 / T$ and $1 / \mathrm{E}(T)$ rules. The $1 / T$ rule starts out with a small withdrawal fraction and remains moderate for many years before rapidly increasing to reach a benefit-to-wealth ratio of one at age $T=100$, i.e. the maximum age assumed in our utility analysis. By contrast, the $1 / \mathrm{E}(T)$ rule starts with a moderate withdrawal percentage and is less convex than the $1 / T$ rule; consequently the $1 / \mathrm{E}(T)$ path involves an earlier portfolio drawdown as compared to the $1 / T$ rule.

Figure 1 here

Expected Benefits and Value at Risk under Alternative Payout Patterns. A retiree who pursues a phased withdrawal plan must allocate her remaining assets across a portfolio of stocks and bonds. To model the payout implications of alternative investment choices, we assume that the

\footnotetext{
${ }^{8}$ The first rate $\left(\omega\right.$-rule) is then equal to the $1 / \ddot{a}_{x+t}$ rule used in Blake et al. 2003 and in Milevsky and Young 2002.

${ }^{9}$ This assumes $\mathrm{p}_{\mathrm{x}}$ is the conditional probability that an $\mathrm{x}$-year old woman will attain age $\mathrm{x}+\mathrm{t}$, so the complete expectation of life is calculated as $\mathrm{E}[T(x+t)]=\sum_{t=0}^{w-x}{ }_{t} p_{x}$.
} 
stochastic dynamics of the market returns of both asset classes follow a multi-dimensional geometric random walk with drift. We calibrate the model for US data, using time series for large cap equities and long term bonds ranging from 1974 to 2004 (details appear in Appendix A). We assume that the retirement assets are rebalanced continuously to maintain an equity/bond asset split of $60 / 40 \%$, as this is commonly recommended by financial advisers for retirement portfolios.

Figure 2 compares expected benefit paths for the various distribution programs to the life annuity profile, conditional on survival. Focusing first on the fixed benefit rule, in the first year of her retirement, the retiree's mean benefits equal her life annuity payout; this is sensible as this rule was designed to mimic the fixed life annuity until funds are exhausted. At some point, however, expected payments must decrease, reflecting the risk of running out of money. The fixed percentage rule also starts in the first year with a benefit equal to the life annuity payout, by construction. Thereafter, mean benefits rise as the retiree ages, because the pension account's expected gross rate of return exceeds the constant benefit-to-wealth-ratio.

Figure 2 here

The other two payout patterns behave somewhat differently. Compared to the other payout plans, the $1 / T$ rule offers lower expected benefits until age 74 , but expected benefits rise extremely quickly after that, and to very high levels. This occurs because the $1 / T$ rule pays the retiree only a small amount of money during the first part of the retirement period, in fact, less than her portfolio's annual expected return. Accordingly, the retiree continues to build up saving in earlier years which can boost her expected benefits later. The $1 / \mathrm{E}(T)$ rule begins with a lower annual payout, which then rises above the fixed annuity payment when the retiree is still rather young (age 69). Thereafter, the 1/E(T) benefits peak (at age 88) and decline; as less wealth remains in the account, at some point expected benefits must fall, although the withdrawal fraction increases.

It is also instructive to report a "worst-case" risk measure for the phased withdrawal plans. Figure 3 depicts the probable minimum benefit (to a confidence level of $\alpha=1 \%$ ) compared to the life annuity profile. This PMB metric is defined as follows:

$$
\mathrm{P}\left(B_{t}<\mathrm{PMB}_{t, 1-\alpha}\right)=\alpha=1 \%
$$

The $\mathrm{PMB}_{t, 99 \%}$ of a distribution program represents the first percentile of the payout distribution in each period, conditional on survival. In other word, if the retiree is still alive $t$ years after 
retirement, she would receive a payout from the payout program equal to or higher than the

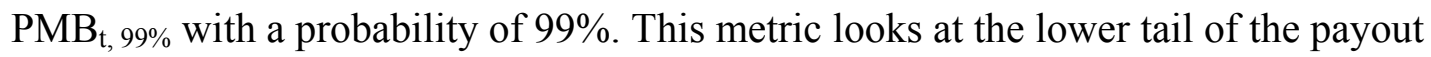
distribution, so it can be interpreted as a worst-case risk measure.

Figure 3 here

It is important to note that, initially, the probable minimum benefit for the fixed benefit rule is the same as the annuity payment, but it quickly falls over time and becomes zero at age 80 , i.e. the retiree runs out of money. By contrast, the benefits in worst-case situations for all the variable withdrawal plans are well below the annuity payments during the first 20 years of retirement. The probable minimum benefits of the $1 / T$ as well as of the $1 / E(T)$ rules are much lower than the annuity payment early on, and they increase thereafter. At age 85, the probable minimum benefit for the $1 / T$ even exceeds the annuity payment. On the contrary, the $1 / \mathrm{E}(T)$ rule never exceeds the annuity payment. The probable minimum benefit of the fixed percentage rule remains at a very low level and never recovers. In summary, all the distribution programs examined incorporate worst-case risk profiles that are remarkably high for retirees.

\section{A Utility Approach to Distribution Rules}

The expected benefit and the probable minimum benefit metrics described above are useful in exploring risk/return tradeoffs of different payout strategies. Next we turn to a utilitybased approach which permits us to assess how a retiree might evaluate these distribution programs while taking into account risk aversion and time preference.

Impact of Risk Aversion on the Choice of Distribution Rule. To understand how the various distribution patterns would be assessed by people with different levels of risk aversion, we adopt an additively time-separable utility function of the Constant Relative Risk Aversion (CRRA) class. ${ }^{10}$ As above, $B_{t}$ denotes the nominal level of benefits from a phased withdrawal plan, while $A_{t}$ represents the benefits from a life annuity at time $t$. Here $V_{t}$ represents the value of the remaining assets in the retirement account, which also represents the bequest should the retiree die. We assume the retiree's objective function $U$ is defined over total benefits received and bequest left at death, and it takes the form: ${ }^{11}$

\footnotetext{
${ }^{10}$ This value function is also consistent with other studies which investigate payout strategies including annuities; c.f. Table 1 as well as Dushi and Webb(2004) and Milevsky and Young (2003).

${ }^{11}$ In our model setup, the retiree uses all payouts only for consumption purposes.
} 


$$
U=E\left[\sum_{t=0}^{K}\left(\prod_{i=0}^{t-1} p_{x+i}^{s}\right)\left[\beta^{t} \cdot p_{x+t}^{s}\left(\frac{\left(B_{t}+A_{t}\right)^{1-\gamma}}{1-\gamma}\right)+k \cdot \beta^{t}\left(1-p_{x+t}^{s}\right)\left(\frac{V_{t}^{1-\gamma}}{1-\gamma}\right)\right],\right.
$$

where $\beta$ reflects the time preference of the investor (set to 0.96, in line with Blake et al. 2003). The strength of the bequest motive is represented by $k$ (which can range from 0 to 1 ). The utility of benefits in period $t$ is weighted by the conditional probability $p_{x}$ that a woman of age $x$ at the beginning of the retirement phase is still alive at $t$. The parameter $\gamma$ reflects the individual's coefficient of relative risk aversion (RRA) and also her willingness to engage in intertemporal substitution in consumption. The parameter plays an important role in evaluating the various distribution programs when the payouts are uncertain because of stochastic asset returns. In what follows, we report results using a range of risk aversion coefficients from 1 to 10 . We classify as least risk averse those with $\gamma$ below 1; the moderately risk averse have $\gamma$ from 1 to 5 ; and very risk averse individuals have $\gamma$ above $5{ }^{12}$

Implementing this approach requires that we first select the optimal static (but continuously rebalanced) asset allocation of stocks and bonds for each withdrawal rule, for each level of risk aversion, and holding other parameters fixed. Next, we compute analytically the expected lifetime utility given this asset allocation pattern for each phased withdrawal rule (except for the fixed benefit rule). We then transform this utility level into an equivalent nominal annuity income stream for life. ${ }^{13}$ The resulting certainty equivalents can then be directly compared to the nominal life annuity benchmark. Finally, as a benchmark for the conventional payout pattern, we also compute an optimal (variable) withdrawal plan for an individual without access to an annuity market for every level of risk aversion using stochastic dynamic programming. The stochastic component of the problem arises from uncertainty regarding date of death as well as uncertain asset returns. This means that we select both the optimal withdrawal pattern for $\omega_{t}$ and its associated asset allocation path to maximize the expected lifetime utility function given in (6) (see Appendix B for detail). The annuity-equivalent income stream can be interpreted as the lifelong nominal annuity stream that would provide the same level of lifetime utility to the retiree, if she lacked access to an annuity market.

\footnotetext{
${ }^{12}$ To price the annuity, we use female annuitant mortality tables from the Society of Actuaries; the female 2000 Population mortality table is used to weight utility (see www.soa.org).

${ }^{13}$ See Cocco et al. (2005) for a similar use of the equivalent constant consumption stream (equivalent annuity stream).
} 
Figure 4 displays the results. ${ }^{14}$ The graph confirms that risk aversion plays an important role in influencing the preferred payout (as in Brown et al. 2001). Furthermore, the fixed benefit rule is consistent only with very low levels of risk aversion $(<1)$, as it exposes the retiree to the risk of outliving her assets. Also at those risk aversion levels, the fixed benefit approach is dominated by all the other payout rules and the annuity path as well. Surprisingly, the fixed percentage rule is preferred across a wide spectrum of risk preferences. It dominates the $1 / T$ rule for all levels of risk aversion considered, and it is more appealing than the annuity for low/moderate levels of risk aversion. In this sense, our findings are supportive of those in the financial planning industry who propose such a fixed benefit rule.

Figure 4 here

We also find that the $1 / T$ rule is clearly the least preferred of all the variable payout rules. By contrast, the $1 / \mathrm{E}(T)$ rule does appeal to low and moderately risk averse retirees, but it is unfavorable for the very risk averse. For extremely high levels of risk aversion, the $1 / \mathrm{E}(T)$ rule is the least attractive of all variable payout rules. The optimal withdrawal plan provides higher utility for low/moderate retires than the other payout rules and also than the annuity. Only the very risk-averse will find the fixed annuity appealing, given these parameters.

To illustrate the relative magnitudes, consider a 65 -year old retiree with moderate risk aversion $(\gamma=3)$. Relative to buying an annuity, she would be $16.8 \%$ better off if she selected the fixed percentage rule; $34.7 \%$ worse if she adopted the $1 / T$ rule; $9.7 \%$ better if she adopted the $1 / \mathrm{E}(T)$ rule; and $30.4 \%$ better if she selected the optimal withdrawal plan. For the extremely riskaverse retiree $(\gamma=9)$, relative to buying an annuity, she would be $17.6 \%$ worse off if she selected the fixed percentage rule; $52.4 \%$ worse if she adopted the $1 / T$ rule; $63.4 \%$ worse off if she adopted the $1 / \mathrm{E}(T)$ rule; and $3.1 \%$ worse if she selected the optimal withdrawal plan.

Figure 5 shows the optimal asset allocation associated with each payout program. First, we show that the asset allocation for the fixed benefit rule (relevant only to the extremely risk preferring) has equity exposure of about $47 \%$. Second, the asset allocation pattern is identical for all of the variable phased withdrawal plans, but the pattern varies with $\gamma$. For values of risk aversion up to 2 , the retiree holds $100 \%$ equities, and as risk aversion rises, her preferred equity

\footnotetext{
${ }^{14}$ Similar to the case without a bequest motive, we computed certainty equivalents for $\mathrm{k}=1$. The level of bequest motive is insensitive to the order of choice regarding a specific retirement rule.
} 
exposure falls. ${ }^{15}$ It is interesting that the $60 / 40 \%$ stock/bond portfolio commonly recommended by financial advisers is appropriate only for those with risk aversion of around 4, but the curve slopes slowly so even very risk averse consumers will still hold $40 \%$ of their assets in equities. Figure 5 here

Blending Portfolios of Annuities and Withdrawal Rules. To determine whether a blended portfolio might provide greater utility than stand-alone strategies, we evaluate approaches that combine both a life annuity product and a phased withdrawal rule. The $1 / \mathrm{E}(T)$ is a natural payout rule to focus on, in view of the fact it mimics the "default" pattern under US tax law. ${ }^{16} \mathrm{We}$ consider first the case where the retiree at age 65 elects how much to annuitize and how much to maintain in her withdrawal account. ${ }^{17}$ Next, we allow the retiree to default into the $1 / \mathrm{E}(T)$ plan at retirement, and then she is permitted to switch the remainder of her wealth into an annuity at some later point. ${ }^{18}$

Figure 6 compares the results in the case where the blending rule must be set at retirement. Those with low risk aversion do not annuitize, but as $\gamma$ rises to 1.5 , the demand for annuities rises strongly. The retiree with $\gamma=4$ invests $62.6 \%$ of her wealth in annuities and $37.4 \%$ is held in the phased withdrawal plan and held in equities. In this sense, the annuity crowds out bonds and the withdrawal plan, as risk aversion rises.

Figure 6 here

Table 2 summarizes results when the retiree stays in the phased withdrawal plan at age 65 yet she is permitted to annuitize completely at some later date; this strategy is now compared to the initial blending strategy. The retiree may defer annuitization if she wants to continue to participate in the equity market, or if she seeks to ensure that she can bequeath some assets to her heirs. ${ }^{19}$ We take the investment weights and the withdrawal fractions from the previous withdrawal analysis and try to determine when she would switch fully into annuities. We constructed intertemporal portfolios of annuities and the $1 / \mathrm{E}(T)$ rule and computed the welfare

\footnotetext{
15 The equity portion never falls to zero, because bonds are also somewhat risky.

${ }^{16}$ Milevsky and Young (2002) find that the optimal withdrawal fraction for a log investor in a deterministic switching blending is identical to the IRA default case if the risk free rate is set to zero. Blake et al. (2003)'s withdrawal rule collapses to the $1 / \mathrm{E}(T)$-rule if the actuarial rate of return is set to zero. Dus et al. (2005) find appealing characteristics of the $1 / \mathrm{E}(T)$-rule in a shortfall framework.

17 The program spans the state space by drawing 10,000 random numbers for each of the 36 retirement years. Then we optimize the fraction invested in bonds and equities as well as the amount used for purchasing a life annuity.

${ }^{18}$ The program spans the state space by drawing 10,000 random numbers for each of the 36 retirement years. Then we compare the utility outcomes for all possible switching ages and select the switching year with the highest utility.

${ }^{19}$ Future work could consider how the purchase of life insurance would change this problem.
} 
gains compared to annuitizing immediately. The welfare loss from annuitizing immediately is equivalent to the real option value of delaying annuitization (christened by Milevsky and Young 2002 the Real Option Value to Delay Annuitization or RODA). The retiree immediately annuitizes if her $\gamma$ exceeds 4.5. For instance, the retiree with moderate risk aversion $(\gamma=3)$ postpones annuitizing her wealth until she turns 80 . Compared to a mandatory annuitization at age 65 , she gains almost $11 \%$ from deferring annuitization for 15 years. As risk aversion decreases, the utility gain over the benchmark rises substantially as well as the related switching age.

\section{Table 2 here}

The magnitude of the welfare gains for different levels of risk aversion that we estimate are in line with those from Milevsky (2006) and Milevsky and Young (2002), though our capital market model allows for more realism and our withdrawal rule follows the "default" pattern mandated by the US tax law. Making switching mandatory at a certain age, say at age 75 as was true in the UK until recently, penalizes everyone that has a lower risk aversion than $\gamma=3.5$. A switching age of 85 as in Germany, however, does not harm any retiree who considers a complete switching strategy. Constructing portfolios over time works well for risk preferring retirees, but moderate to extremely risk-averse retirees will benefit from blending withdrawal strategies and life annuities initially. Even a retiree with a risk aversion of 10 would still hold a very small fraction of her assets in a phased withdrawal plan, in order to be better off by almost $4 \%$ compared to immediate and complete annuitization.

The preceding analysis has assumed that the retiree initially determines her optimal switching age and does not account for future circumstances. Accordingly, next we let the retiree react to changes in the yield curve using dynamic programming techniques. ${ }^{20}$ Figure 7 shows the resulting switching frontiers for two different retirees. The lower left region of the frontier indicates the area in which the retiree will want to continue to withdraw assets from her retirement account. The upper right area shows the region in which the retiree has already annuitized her assets because the short rate realization has been sufficiently high. Not surprisingly, the higher the interest rate, the sooner the retiree annuitizes her entire asset base.

\footnotetext{
${ }^{20}$ The expectation operator in the Bellman equation is computed by resorting to Gaussian quadrature integration and by cubic-splines interpolation. We then derive the optimal annuitization age by comparing the value of continuing with the $1 / \mathrm{E}(T)$ withdrawal plan to the utility derived from switching to life-annuities completely. We used 40 states for the short rate and a binary indicator variable $I_{\mathrm{t}}$ to determine the "switching into life annuities" strategy.
} 
However, a more risk-loving retiree will also demand a higher short rate than her risk-averse counterpart. The switching frontier itself is concave because the mortality credit increases over time and replaces cost advantages formerly generated by the related short rate. Accordingly, Figure 7 shows the combined effect of interest rate level and mortality credit. The lower is risk aversion, the higher the short rate must be to induce the retiree to annuitize her assets.

Figure 7 here

Further Results. This section describes other results of policy interest (not reported here in detail but available on request). First, disregarding administrative costs included in the insurance premium only modestly alters our results. Second, we have also computed certainty equivalence values for the various payout strategies assuming a positive bequest motive. Of course, all withdrawal plans seem more appealing once a bequest motive is taken into account. Further, the lower the level of risk aversion, the larger the gains resulting from applying a particular withdrawal rule. For instance, the fixed benefit approach becomes $57 \%$ more attractive with a bequest motive, compared to the equivalent annuity stream. Full annuitization at the beginning of the retirement period is inapplicable for $\gamma \geq 1$. Nevertheless, the level of the bequest motive is insensitive to the order of choice regarding specific retirement rules.

Last, we have also examined the sensitivity of results to asymmetry of mortality beliefs. Assuming that the $1 / \mathrm{E}(T)$ rule is adjusted for higher survival probabilities with age, the female retiree who was exactly as healthy as the insurance company assumed when it set the annuity premium would annuitize her wealth earlier. Conversely a retiree in worse-than-average health would tend to postpone annuitization by up to two years, depending on her level of risk aversion. But if, due to regulatory reasons, the $1 / \mathrm{E}(T)$ rule is not adjusted for higher survival probabilities, retirees would prefer to annuitize later. Accordingly, this example shows that asymmetry regarding mortality beliefs can contribute to explaining why individuals who believe themselves to be less healthy than average are more likely to postpone annuitization.

\section{Conclusions and Discussion}

Global disintermediation trends imply that workers are increasingly reaching retirement age with substantial retirement accumulations which they will be called on to manage themselves. As a result, they need advice how to optimally convert accumulated assets into a stream of retirement income so as not to exhaust their funds too soon. Our utility framework 
enables us to compare the value of purchasing a stand-alone life annuity, versus a phased withdrawal strategy backed by a properly diversified investment portfolio, as well as combinations of these two tactics. We show that the appropriate mix depends on retiree attitudes toward risk (as well as the underlying economic and demographic assumptions). Specifically, comparing withdrawal rules often cited by financial planners and policymakers, such as the $1 / \mathrm{E}(T)$, the fixed percentage, the $1 / T$, and the fixed benefit rule, we find that:

- Somewhat surprisingly, the fixed percentage rule is appealing for retirees across a wide range of risk preferences. In this sense, this rule is supportive of some in the financial advice industry who propose such a rule.

- The $1 / \mathrm{E}(T)$ rule appeals to low/moderately risk-averse retirees, but it is unfavorable for the very risk-averse. The fixed benefit rule is not appealing for most retirees as it exposes them to the risk of outliving their assets, while the $1 / T$ performs worse than any other variable withdrawal rule for a broad range of investors.

- For the three variable distribution plans, the optimal asset allocation is identical given a risk aversion level. Specifically, for low risk aversion, equities dominate and bonds play a greater role as risk aversion rises. By contrast, in the fixed benefit case, even risk-averse retirees are led to hold high fractions in bonds.

Next, we compare stand-alone withdrawal rules versus immediate annuitization of the entire portfolio. Consistent with previous studies, we show that annuities are attractive as a stand-alone product when the retiree has sufficiently high risk aversion and lacks a bequest motive. Withdrawal plans dominate annuities for low/moderate risk preferences, because the retiree can gain by investing in the capital market and from "betting on death."

Finally, we examine combination/mixed strategies where retirees may both invest some of their assets and also buy a payout annuity. In the case where the annuitization decision occurs at the point of retirement, we find that:

- Annuities become appealing for those with moderate risk aversion, when retirees can hold both annuities and phased withdrawal plans as a mixed strategy. Withdrawal plans are now attractive for highly risk-averse retirees.

- From an asset allocation perspective, annuities first crowd out bonds when risk aversion rises. As risk aversion increases further, annuities replace equities in the overall portfolio. 
When a retiree is permitted to switch into an annuity at some point after the retirement date, we find that the optimal annuitization age is sensitive to the degree of risk aversion and interest rates in the following manner:

- Less risk-averse retirees will wait longer until they switch to an annuity.

- Very risk-averse individuals will be willing to annuitize in a low interest rate environment, but higher interest rates are required to induce annuitization among risk preferrers.

Our results are relevant to a wide range of financial service providers and regulators in the retirement marketplace. Money managers and insurers should note that many retirees hold suboptimal asset allocations, as we show that annuities first crowd out bonds as risk aversion rises, and at higher levels of risk aversion, they replace equities in the retiree's portfolio. Making annuitization compulsory can also lead to substantial utility losses for less risk-averse investors, if annuitization is forced too early. But it would appear that annuitization at age 85 could be a sensible annuitization point if bequest motives are disregarded (and given our model parameterizations). Mandatory annuitization has recently been implemented in Germany at exactly this age for tax-sheltered Riester Personal Pension accounts; and in the U.S. compulsory annuitization was recommended by the recent Commission to Strengthen Social Security.

Thus far our model indicates that retirees find equity-linked phased withdrawal plans attractive because investors are assumed to access the equity market only by using a phased withdrawal plan. This assumption is realistic, insofar as in the US most payout annuities are nominal (Brown et al. 2001). Future research will explore the role of equity-linked variable payout annuities in retiree portfolios, to the extent that they complete the underlying asset structure by including an equity premium and a mortality credit. 


\section{References}

Albrecht, P. and R. Maurer, 2002, Self-Annuitization, Consumption Shortfall in Retirement and Asset Allocation: The Annuity Benchmark. Journal of Pension Economics and Finance, 1 (3), 269-288.

Ameriks, J., R. Veres and M. J. Warshawsky, 2001, Making Retirement Income Last a Lifetime. Journal of Financial Planning, December, 60-76.

Babbs, S. H. and K.B. Nowman, 1999, Kalman Filtering of Generalized Vasicek-Term Structure Models. The Journal of Financial and Quantitative Analysis, 34 (1), 115-130.

Bengen, W.P., 1994, Determining Withdrawal Rates Using Historical Data. Journal of Financial Planning, 7 (4), 171-180.

Bengen, W.P., 1997, Conserving Client Portfolios During Retirement, Part III. Journal of Financial Planning, 10 (6), 84-97.

Bernheim, B.D., 1991, How Strong are Bequest Motives? Evidence Based on Estimates of the Demand for Life Insurance and Annuities. Journal of Political Economy, 99 (5), 899-927.

Blake, D., A.J.G. Cairns , and K. Dowd, 2003, PensionMetrics II: Stochastic Pension Plan Design During the Distribution Phase. Insurance: Mathematics and Economics, 33 (1), 29-47.

Brown, J.R. and J. M. Poterba, 2000, Joint Life Annuities and Annuity Demand by Married Couples. Journal of Risk and Insurance, 67 (4), 527-553.

Brown, J.R., O.S. Mitchell, and J. M. Poterba, 2001, The Role of Real Annuities and Indexed Bonds in an Individual Accounts Retirement Program, in: In Risk Aspects of InvestmentBased Social Security Reform. Chicago. University of Chicago Press.

Brugiavini, A., 1993, Uncertainty Resolution and the Timing of Annuity Purchases. Journal of Public Economics, 50 (1), 31-62.

Chen, P. and M.A. Milevsky, 2003, Merging Asset Allocation and Longevity Insurance: An Optimal Perspective on Payout Annuities. Journal of Financial Planning, 16(6), 52-62.

Cocco, J.F., F.J. Gomes, and P.J. Maenhout, 2005, Consumption and Portfolio Choice over the Life-Cycle. Review of Financial Studies, 18 (2), 491-533.

Cogan, J. and O.S. Mitchell, 2003, Perspectives from the President's Commission on Social Security Reform. Journal of Economic Perspectives, 17 (2), 149-172.

Davidoff, T., J.R. Brown, and P.A. Diamond, 2005, Annuities and Individual Welfare. American Economic Review, 95 (5), 1573-1590.

Dus, I., R. Maurer, and O.S. Mitchell, 2005, Betting on Death and Capital Markets in Retirement: A Shortfall Risk Analysis of Life Annuities versus Phased Withdrawal Plans. Financial Services Review 14, 169-196.

Dushi, I. and A. Webb, 2004, Household Annuitization Decisions: Simulations and Empirical Analysis, Journal of Pension Economics and Finance, 3 (2), 109-143.

Feldstein, M., E. Ranguelova, and A. Samwick, 2001, The Transition to Investment-Based Social Security When Portfolio Returns and Capital Profitability are Uncertain. In: Risk Aspects of Investment-Based Social Security Reform. Chicago. University of Chicago Press, 4181.

Ho, K., M. Milevsky, and C. Robinson, 1994, Asset Allocation, Life Expectancy and Shortfall. Financial Services Review 3 (2), 109-126.

Hughen, J.C., F.E. Laatsch, and D.P. Klein, 2002, Withdrawal Patterns and Rebalancing Costs for Taxable Portfolios. Financial Services Review 11 (4), 341-366. 
Hurd, M.D. and J. P. Smith, 1999, Anticipated and Actual Bequests, NBER Working Papers 7380, National Bureau of Economic Research, Inc.

Kapur, S. and J.M. Orszag, 1999, A Portfolio Approach to Investment and Annuitization During Retirement. Mimeo, Birbeck College, University of London, London, UK.

Kingston, G. and S. Thorp, 2005, Annuitization and Asset Allocation with HARA Utility, Journal of Pension Economics and Finance, 4 (3), 225-248.

Merton, R. C., 1971, Optimum Consumption and Portfolio Rules in a Continuous Time Model. Journal of Economic Theory 3 (4), 373-413.

Merton, R.C., 1983, On Consumption Indexed Public Pension Plans. In: Bodie, Z., Shoven, J. (Eds.), Financial Aspects of the US Pension System, University of Chicago Press, Chicago, (Reprinted as Chapter 18 of Merton (1990)).

Merton, R. C., 1990, Continuous Time Finance, Blackwell, Cambridge, MA.

Milevsky, M.A., 1998, Optimal Asset Allocation Towards the End of the Life Cycle: To Annuitize or Not to Annuitize? Journal of Risk and Insurance 65 (3), 401-426.

Milevsky, M.A., 2001, Optimal Annuitization Policies: Analysis of the Options. North American Actuarial Journal, 5, 57-69.

Milevsky, M.A., 2006, The Calculus of Retirement Income: Financial Models for Pension Annuities and Life Insurance. Cambridge.

Milevsky, M.A., K. Ho, and C. Robinson, 1997, Asset Allocation Via the Conditional First Exit Time or How to Avoid Outliving Your Money. Review of Quantitative Finance and Accounting, 9 (1), 53-70.

Milevsky, M.A. and C. Robinson, 2000, Self-Annuitization and Ruin in Retirement. North American Actuarial Journal, 4, 112-129.

Milevsky, M.A. and V.R. Young, 2002, Optimal Asset Allocation and The Real Option to Delay Annuitization: It's Not Now-or-Never, The Schulich School of Business, December, York University, Canada [11.02.2006] http://www.ifid.ca/pdf workingpapers/ ].

Milevsky, M.A. and V.R. Young, 2003, Annuitization and Asset Allocation. Working Paper IFID Centre, The Schulich School of Business, December, York University, Canada [11.02.2006] http://www.ifid.ca/pdf workingpapers/ ].

Milevsky, M.A., K.S. Moore, and V.R. Young, 2006, Optimal Asset Allocation and RuinMinimization Annuitization Strategies, Mathematical Finance, to appear.

Mitchell, O. S., J. M. Poterba, M. J. Warshawsky and J. R. Brown, 1999, New Evidence on the Money's Worth of Individual Annuities. American Economic Review, 89 (5), 1299-1318.

Polyak, I., 2005, New Advice to Retirees: Spend More at First, Cut Back Later. New York Times, September 25, 2005.

Pye, G. B., 2000, Sustainable Investment Withdrawals. Journal of Portfolio Management, Summer, 26 (4) 73-83.

Pye, G. B., 2001, Adjusting Withdrawal Rates for Taxes and Expenses. Journal of Financial Planning, April, 14 (4) 126-136.

Stabile, G., 2003, Optimal timing of the Annuity Purchases: A Combined Stochastic Control and Optimal Stopping Problem. Working Paper, Universita degli Studi di Roma, Rome, Italy.

Whitaker, B., 2005, Managing Retirement, After You Really Retire. New York Times, October $16,2005$.

Yaari, M. E., 1965, Uncertain Lifetime, Life Insurance, and the Theory of the Consumer. Review of Economic Studies, 32, 137-150. 


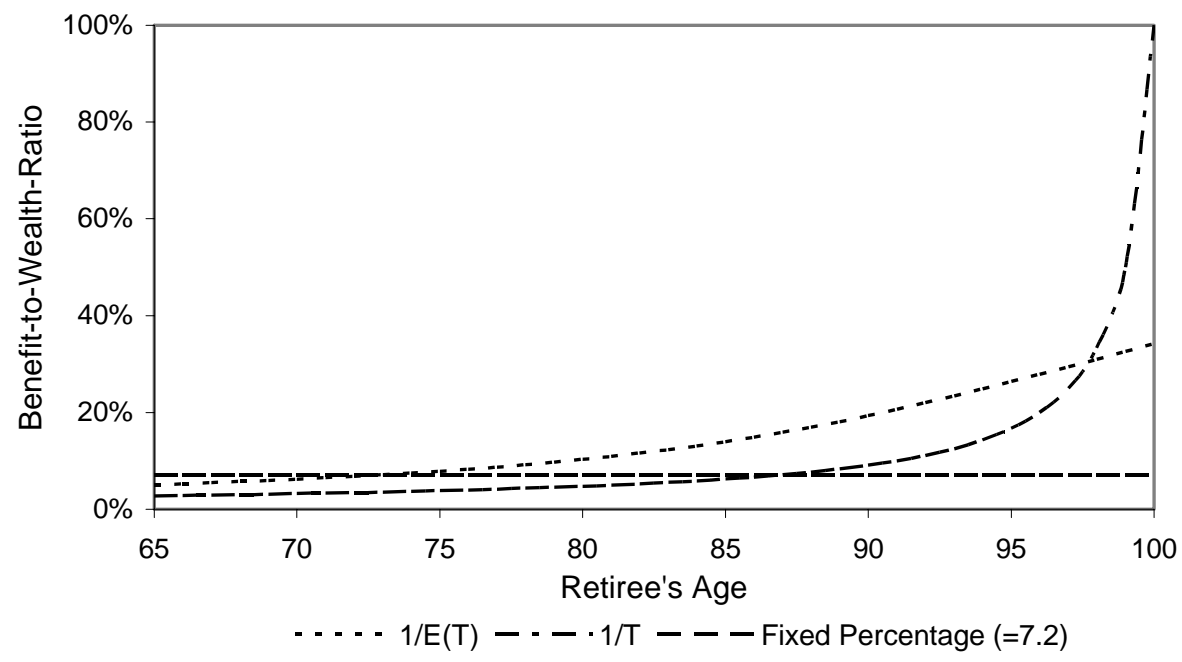

Figure 1. Benefit-to-Wealth Patterns for Alternative Phased Distribution Rules

This figure displays benefit-to-wealth ratios for the three variable withdrawal rules of interest. The $1 / \mathrm{E}(T)$ path is represented by a dotted line; the $1 / T$ rule is a dash/dot line, and the fixed percentage rule (set here at $7.2 \%$ ) is represented by a dashed line.

Source: Authors' calculations.

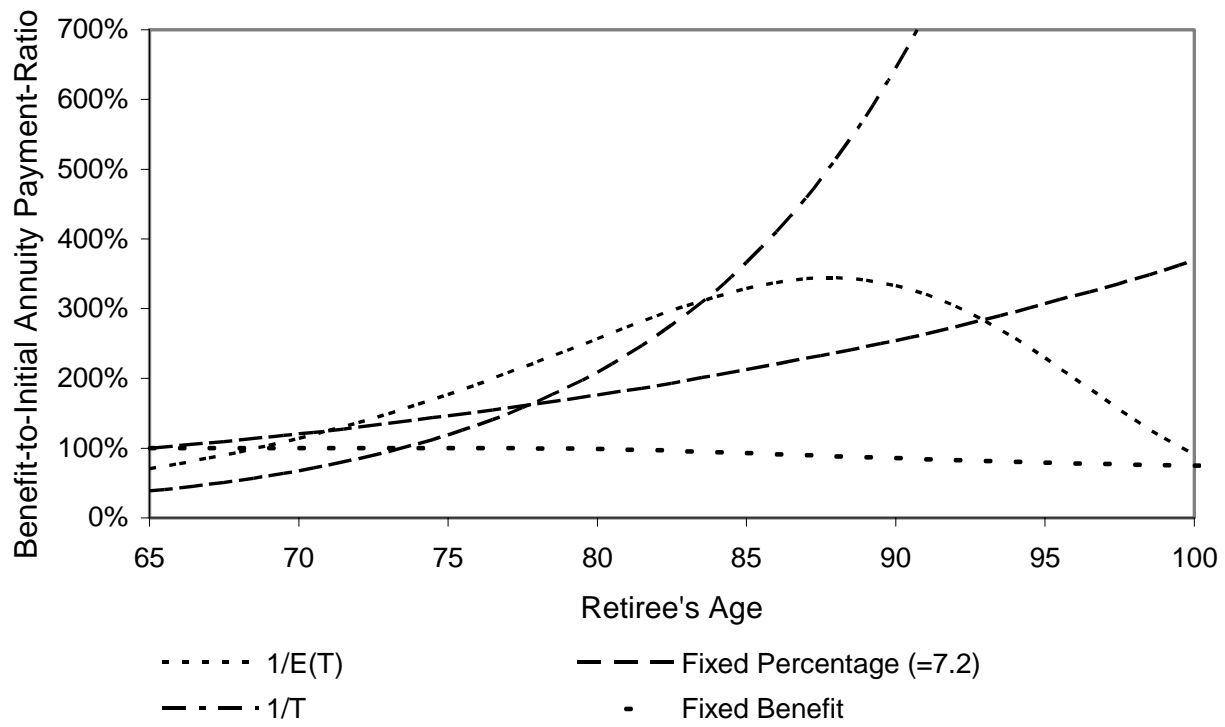

Figure 2. Expected Benefit Ratios for Alternative Distribution Rules Conditional on Survival

This figure compares expected benefits under the three withdrawal rules (conditional on survival) to the life annuity profile. The dotted line reflects expected consumption levels for the $1 / \mathrm{E}(T)$ rule; the dashed line shows the same for the fixed percentage rule. The dash/dot line represents the $1 / T$ withdrawal path, wile the bold dashes reflect the expected fixed benefit path. The underlying asset allocation is a $60 / 40 \%$ split (stocks/bonds) and values are expressed as a fraction of the life annuity payouts.

Source: Authors' calculations. 


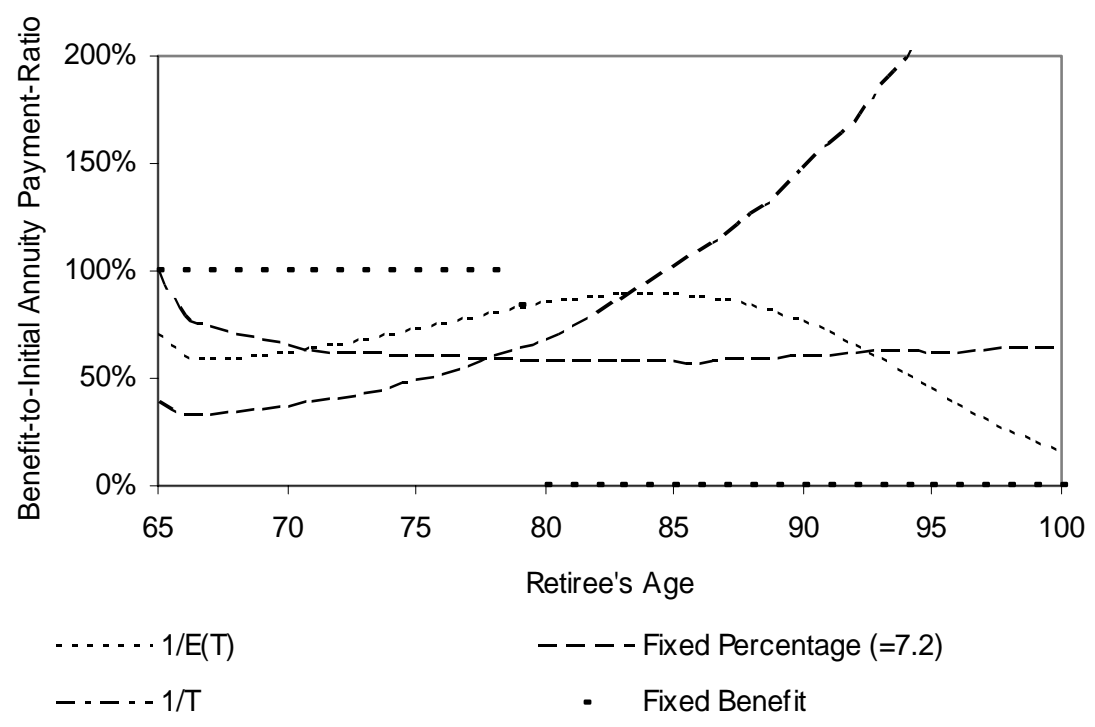

Figure 3. Probable Minimum Benefits under Alternative Distribution Rules Conditional on Survival This figure indicates probable minimum benefits (at the 1 percentile level) or 'downside risk' for the three withdrawal rules. The dotted line shows the $1 / \mathrm{E}(T)$ rule downside risk; the dashed line represents the fixed percentage downside risk. The dash/dot line represents the probable minimum benefit for the $1 / T$ withdrawal rule and the bold dashes reflect the downside risk of the fixed benefits. The underlying asset allocation is a $60 / 40 \%$ split (stocks/bonds ) and values are expressed as a fraction of the life annuity payouts.

Source: Authors' calculations.

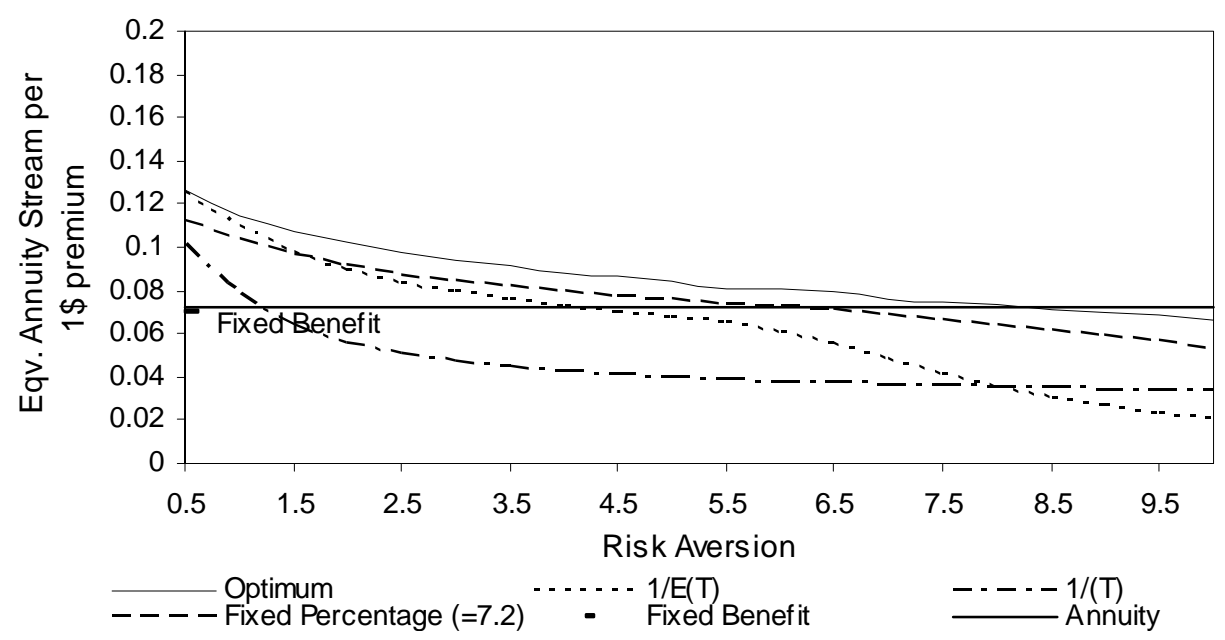

Figure 4. Equivalent Annuity Streams for Alternative Distribution Rules

This figure reports the annuity-equivalent income stream or the lifelong nominal annuity stream providing equivalent lifetime utility to the retiree if she lacked access to an annuity market. For each level of risk aversion $(\gamma)$, the thin solid line displays the equivalent annuity stream of the optimal withdrawal strategy. The dotted line shows the equivalent annuity stream for the $1 / \mathrm{E}(T)$ rule, while the dashed line represents the same for the fixed percentage withdrawal rule. The dash/dot line represents the equivalent annuity stream for the $1 / T$ withdrawal strategy, and the bold dashes refer to the fixed benefit rule. The bar at the ordinate shows the equivalent annuity stream in the case of a self-annuitization strategy; the thick solid line refers to the recurring payout of a life annuity purchased at age 65 . Source: Authors' calculations. 


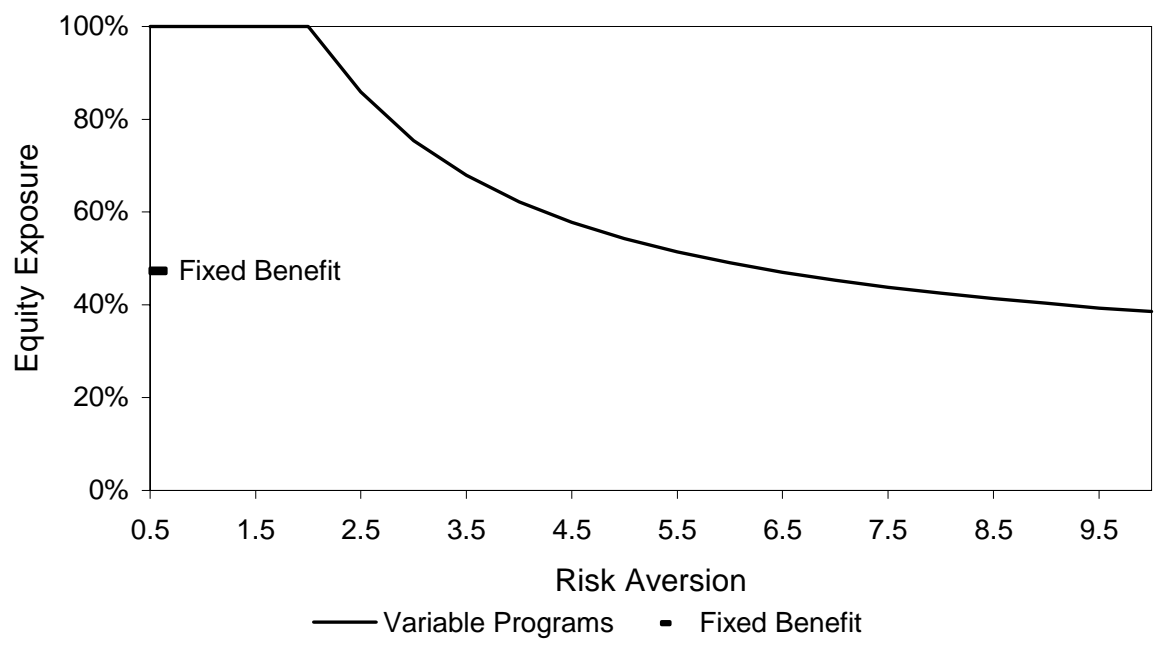

Figure 5. Optimal Equity Exposure for Alternative Distribution Rules

This figure indicates the optimal asset allocation associated with each payout program. The solid line shows the optimal fraction invested in equity if the plan includes variable benefits. The bar at the ordinate represents the optimal fraction invested in equity in case of the fixed benefit plan.

Source: Authors' calculations.

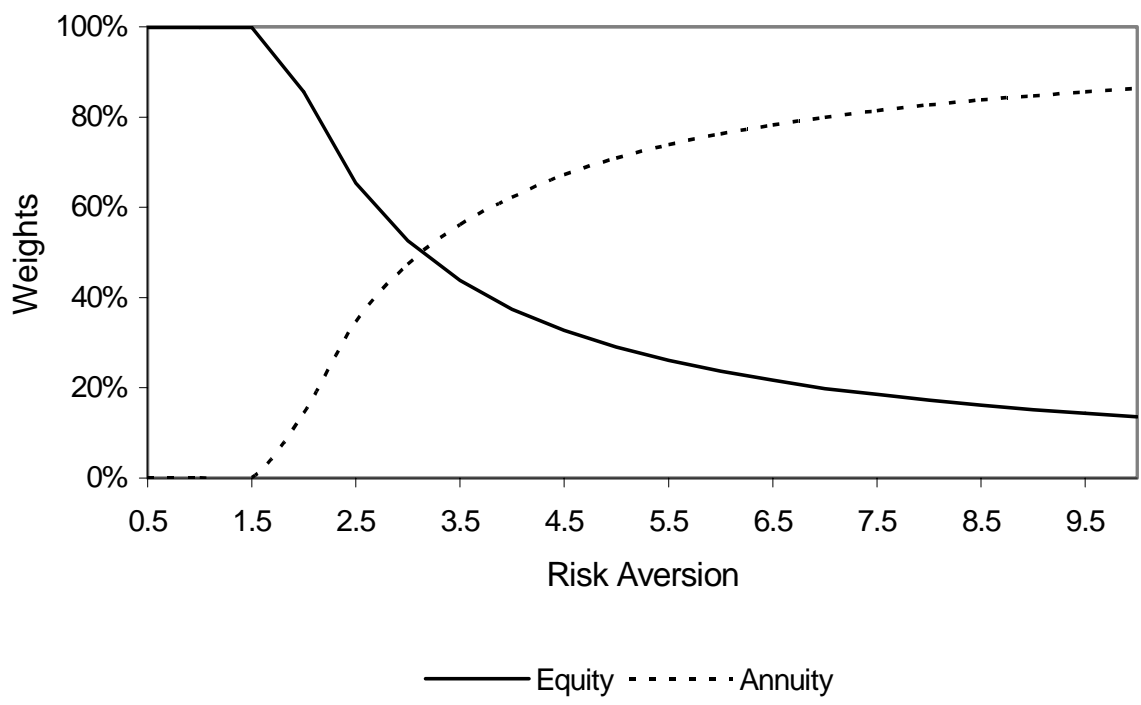

Figure 6. Optimal Blend of Equity and Annuity Given One-Time Decision at Retirement for the 1/E(T) Rule The graph shows, for different levels of risk aversion, the optimal blend of equity and annuities under the 1/E $(T)$ rule. The solid line displays the optimal fraction invested in equity; the dotted line represents the initial amount used for purchasing a life annuity at the age of 65 .

Source: Authors' calculations. 


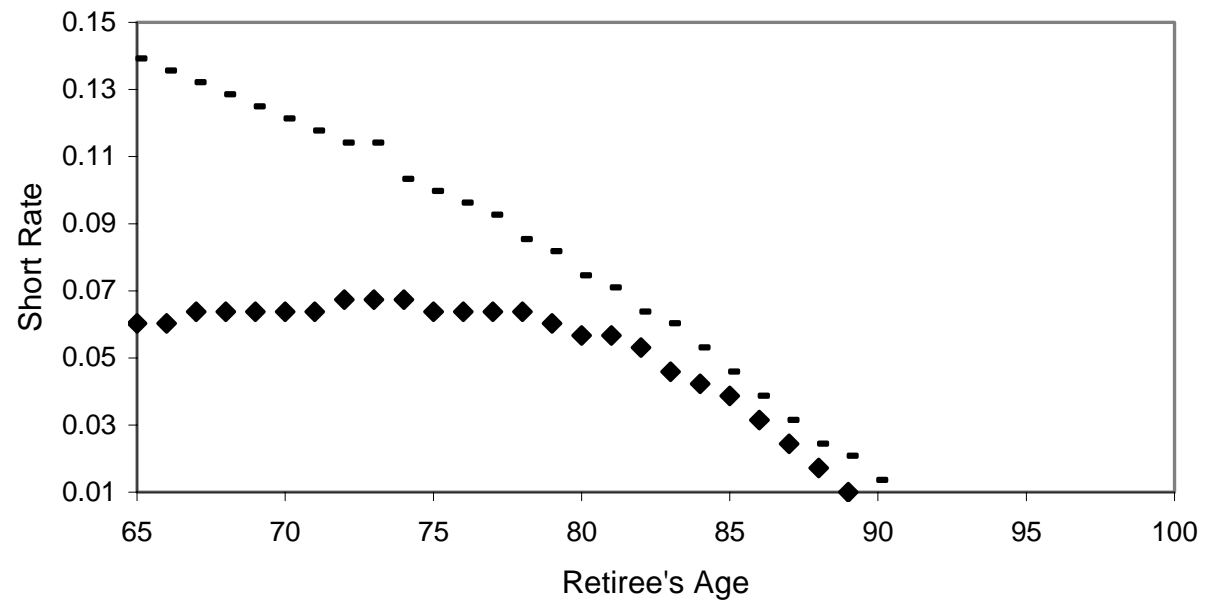

- Risk Aversion (=3) - Risk Aversion (=0.5)

Figure 7. Optimal Switch To Annuities By Age Under the 1/E(T) Rule by Risk Aversion

This figure shows the optimal switching path with age, for retirees with lower and higher risk aversion. The solid bars display the switching frontier for $\gamma=0.5$; the black diamonds stand for the switching frontier that would apply to a retiree with $\gamma=3$. The lower left-hand side of the figure indicates the withdrawal region, and the upper right side shows the annuitization region.

Source: Authors' calculations. 


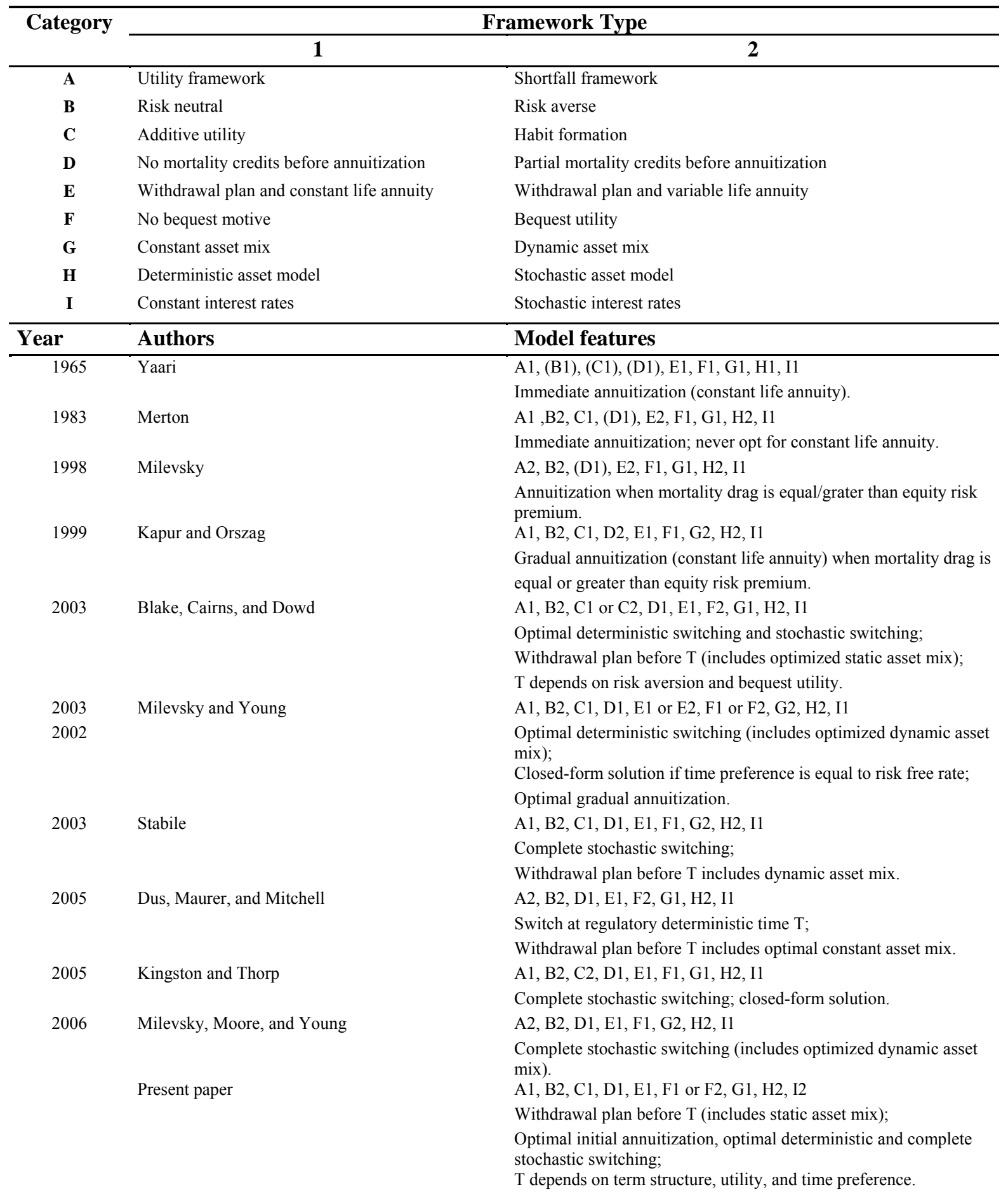

Table 1. Retirement Payout Research Overview: Assumptions and Specifications

The top panel describes the range of assumptions used in prior studies as well as the present analysis. The lower panel employs this structure to categorize relevant studies combining life annuities and phased withdrawal plans. Source: Adapted from Blake et al. (2003) with the addition of categories A, C, and I. 


\begin{tabular}{|c|c|c|c|c|c|c|c|c|c|c|c|}
\hline & \multicolumn{11}{|c|}{ Risk Aversion Level $(\gamma)$} \\
\hline & $\underline{0.5}$ & $\underline{1}$ & $\underline{1.5}$ & $\underline{2}$ & $\underline{2.5}$ & $\underline{3}$ & $\underline{3.5}$ & $\underline{4}$ & $\underline{4.5}$ & $\underline{5}$ & $\underline{10}$ \\
\hline Switching Age & 85 & 84 & 84 & 82 & 81 & 80 & 77 & 75 & 65 & 65 & 65 \\
\hline $\begin{array}{l}\text { Switching/Blending vs. } \\
\text { Annuity at age } 65\end{array}$ & 77.67 & 54.81 & 38.23 & 26.10 & 17.32 & 10.98 & 6.21 & 2.46 & 0 & 0 & 0 \\
\hline $\begin{array}{l}\text { Initial Blending vs. } \\
\text { Annuity at age } 65\end{array}$ & 74.02 & 52.36 & 36.47 & 25.17 & 18.79 & 14.93 & 12.36 & 10.52 & 9.18 & 8.13 & 3.79 \\
\hline
\end{tabular}

Table 2. Percentage Increase in Equivalent Annuity Stream for Blended Strategies

The table shows, for alternative risk aversion levels, the optimal switching age under a $1 / E(T)$ phased withdrawal rule, taking into account the optimal deterministic switching strategy. It also compares the gains in equivalent annuity streams, from a blended switching tactic to that from undertaking immediate complete annuitization at age 65.

Source: Authors' calculations. 


\section{Appendix A: Models and Parameterization}

Interest Rate Model: We assume that the short rate follows an Ornstein-Uhlenbeck process to describe the interest rate exposure of annuities consistently:

$$
d r_{t}^{s}=\kappa_{r}\left(\theta_{r}-r_{t}^{s}\right) d t+\sigma_{r} d W_{r t}
$$

where $r^{s}$ is the short rate, $\theta_{r}$ represents the long run mean, and $\kappa_{r}$ stands for the degree of mean reversion and $\sigma_{r}$ is the volatility of the short rate. The term structure of zero bonds with maturities $\mathrm{t}>0$ is then given by:

$$
B_{t}(\tau)=e^{-a(\tau)-b(\tau) r_{t}^{s}}
$$

with

$$
\begin{gathered}
a(\tau)=y(\infty)\left(\tau-b(\tau)+\frac{\sigma_{r}^{2}}{4 \kappa} b(\tau)^{2}\right), \\
b(\tau)=\frac{1}{\kappa}\left(1-e^{-\kappa \tau}\right), \\
y(\infty)=\theta+\frac{\sigma_{r} \zeta_{r}}{\kappa}-\frac{1}{2} \frac{\sigma_{r}^{2}}{\kappa^{2}} .
\end{gathered}
$$

where $y(\infty)$ denotes the asymptotic zero-coupon yield as time-to-maturity goes to infinity, and $\zeta_{r}$ is the market price of risk. We use the Kalman Filter as applied by Babbs and Nowman (1999) for multifactor term structure models to fit the one-factor Vasicek to the US yield curve data.

Asset Returns: The vector of risky assets (stocks and bonds) $\bar{P}_{t}$ follows a stochastic process of the form:

$$
d \bar{P}_{t}=\operatorname{diag}\left(\bar{P}_{t}\right)\left\lfloor\mu d t+\sum_{=} d \bar{W}_{t}\right\rfloor
$$

where $W=\left(w_{1}, w_{2}\right)^{\prime}$ is a two-dimensional standard Brownian motion, i.e. a vector of two independent Brownian motions. The $(2 \times 2)$ matrix $\underline{\underline{\Sigma}}$ measures the sensitivity of the risky assets to exogenous shocks in such a way that the matrix $\sum \sum^{\prime}$ contains the variance and covariance of the instantaneous rates of return. If the portfolio is rebalanced continuously to keep the fraction invested in different assets constant over time, we can write the portfolio process as a one dimensional Geometric Brownian motion with drift:

$$
d P_{t}=\mu(\pi) P_{t} d t+\sigma(\pi) P_{t} d W_{t}
$$

where

$$
\begin{gathered}
\sigma(\pi)=\sqrt{\left(\Pi^{\prime} \Sigma \Pi\right)} \\
\mu(\pi)=\Pi^{\prime} \mu=\left(\left[\begin{array}{l}
\pi_{1} \\
\pi_{2}
\end{array}\right]^{\prime}\left[\begin{array}{l}
m_{1}+0.5 \cdot v_{1}^{2} \\
m_{2}+0.5 \cdot v_{2}^{2}
\end{array}\right]\right) .
\end{gathered}
$$

Note that $m_{i}$ is the expected value of the $\log$ returns and $v_{i}$ is the standard deviation of asset $i$. $\prod$ is the vector of the individual portfolio weights $\pi_{\mathrm{i}}$. The stochastic differential equation was derived by Merton (1971, 1990) and applied in Feldstein, Ranguelova, and Samwick (2001) for instance. Constant rebalancing is also in line with Merton's (1971) result for investors with CRRA utility. 
Parameter Estimation: Estimated parameters for the Geometric Brownian motion and the Vasicek process are given in the following table:

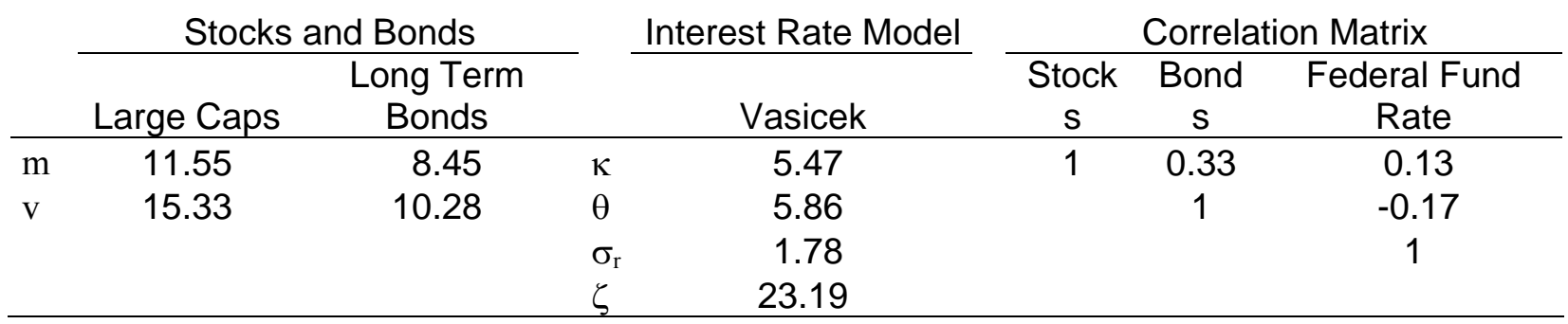

Capital Market Parameterization: The Vasicek model is calibrated by using the monthly yield curve data (06/1974:12/2004) provided by the Federal Reserve. The mean and standard deviation of the $\log$ returns are estimated by using the Ibbotson time series for large caps and long term bonds data ranging from 1974 to 2004. In addition, the correlation matrix for the Cholesky decomposition is estimated using the Federal Funds Rate as an approximation to the unobservable short rate.

Source: Authors' calculations. 


\section{Appendix B: Derivation of Optimal Variable Withdrawal Rule Without Annuities}

Bellman Equation: The multi-period optimization problem can be split into several one-period problems:

$$
U_{t}=p_{x+t} \frac{B_{t}^{1-\gamma}}{1-\gamma}+q_{x+t} k \frac{V_{t}^{1-\gamma}}{1-\gamma}+\beta E_{t}\left[p_{x+t} U_{t+1}\right] .
$$

Restate the absolute terms as fractions of the current period's assets:

$$
U_{t}=p_{x+t} \frac{\left(b_{t} V_{t}\right)^{1-\gamma}}{1-\gamma}+q_{x+t} k \frac{\left(v_{t} V_{t}\right)^{1-\gamma}}{1-\gamma}+\beta E_{t}\left[p_{x+t} U_{t+1}\right] .
$$

Dividing by $V_{t}^{1-\gamma}$ yields

$$
\frac{U_{t}}{V_{t}^{1-\gamma}}=p_{x+t} \frac{b^{1-\gamma}}{1-\gamma}+q_{x+t} k \frac{v_{t}^{1-\gamma}}{1-\gamma}+\beta E_{t}\left[p_{x+t} \frac{U_{t+1}}{V_{t}^{1-\gamma}}\right] .
$$

Using the budget constraint

$$
V_{t}=\frac{V_{t+1}}{\left(1-b_{t}\right) R_{t+1}}
$$

leads to

$$
y_{t}=p_{x+t} \frac{b_{t}^{1-\gamma}}{1-\gamma}+q_{x+t} k \frac{v_{t}^{1-\gamma}}{1-\gamma}+\beta E_{t}\left[p_{x+t} y_{t+1}\left[\left(1-b_{t}\right) R_{t+1}\right]^{1-\gamma}\right] \text {, }
$$

where

$$
y_{t}=\frac{U_{t}}{V_{t}^{1-\gamma}} .
$$

Expected Utility: If the portfolio is rebalanced continuously in order to keep the fraction in each risky asset constant over time, the portfolio return is also log-normal distributed. For the sake of simplicity, we assume that the payout is drawn at the start of each year. Let $\omega_{\mathrm{t}}=B_{t} / V_{t}(t=0,1, \ldots ., n)$ then be a predetermined sequence of benefit-to-wealth ratios $0 \leq \omega_{t} \leq 1$, and define

$$
c \omega_{t}=\prod_{i=0}^{t}\left(1-\omega_{i}\right) .
$$

If the risky asset in the retirement account follows a geometric Brownian motion with drift, the nominal $\log$ returns $I$ will be normally distributed with a mean $\mu(\pi)-0.5 \sigma^{2}(\pi)$ and a variance $\sigma^{2}(\pi)$. For an initial endowment $V_{0}$, the market value of the retiree's account at the beginning of year $t(t=1,2, \ldots, n)$ just before the withdrawal $B_{t}$ for that year can be written as follows:

$$
V_{t}=\left(1-\omega_{t-1}\right) V_{t-1} \exp \left(I_{t}\right)=c \omega_{t-1} V_{0} \exp \left(\sum_{i=1}^{t} I_{i}\right) .
$$

The market value of the retiree's account at the beginning of year $t(t=1,2, \ldots, n)$ just before the withdrawal $B_{t}$ for that year. $V_{t}$ is distributed $\log$-normal, i.e. $\ln \left(V_{t}\right) \sim \mathrm{N}\left(k_{t}, v_{t}^{2}\right)$ follows a normaldistribution with mean $k_{t}=\ln \left[\mathrm{c} \omega_{\mathrm{t}-1} \mathrm{~V}_{0}\right]+t\left[\mu(\pi)-0.5 \sigma^{2}(\pi)\right]$ and variance $v_{t}^{2}=t \sigma^{2}(\pi)$. 
Similarly, the payouts $B_{t}$ at the beginning of each period are also log-normal distributed, i.e. $\ln \left(B_{t}\right) \sim \mathrm{N}\left(n_{t}, v_{t}^{2}\right)$ with parameters $n_{t}=\ln \left[\omega_{t} c \omega_{t-1} V_{0}\right]+t\left[\mu(\pi)-0.5 \sigma^{2}(\pi)\right]$ and variance $v_{t}^{2}=t \sigma^{2}(\pi)$ :

$$
B_{t}=\omega_{t} V_{t}=\omega_{t} c \omega_{t-1} V_{0} \exp \left(\sum_{i=1}^{t} I_{i}\right)
$$

Applying Itô's lemma we obtain the following expression of the utility dynamics:

$$
d U_{t}=(1-\gamma) U_{t}\left(\mu(\pi)-0.5 \gamma \sigma^{2}(\pi)\right) d t+(1-\gamma) \sigma(\pi) U_{t} d W_{t} .
$$

The distribution of $\ln \left(U_{\mathrm{t}}\right)$ can be written as:

$$
\ln \left(U_{t}\right) \sim N\left(\left[(1-\gamma)\left(\mu(\pi)-0.5 \gamma \sigma^{2}(\pi)\right)\right] t-\frac{1}{2}(1-\gamma)^{2} \sigma^{2}(\pi) t+\ln U_{0},(1-\gamma)^{2}\left(\sigma^{2}(\pi)\right) t\right) .
$$

The expected utility gained from the benefits in period $t$ and the expected utility gained from the remaining value of the assets in the retirement account can be expressed in terms of a constant mix portfolio strategy as:

$$
\begin{aligned}
& E\left[U\left(B_{t}\right)\right]=\frac{\left(\omega_{t} c \omega_{t-1} V_{0}\right)^{(1-\gamma)}}{(1-\gamma)} \exp \left((1-\gamma)\left(\mu(\pi)-\frac{1}{2} \gamma \cdot \sigma^{2}(\pi)\right) t\right) \\
& E\left[U\left(V_{t}\right)\right]=\frac{\left(c \omega_{t-1} V_{0}\right)^{(1-\gamma)}}{(1-\gamma)} \exp \left((1-\gamma)\left(\mu(\pi)-\frac{1}{2} \gamma \cdot \sigma^{2}(\pi)\right) t\right) .
\end{aligned}
$$

